\title{
The incidence of scarring on the dorsum of the hand
}

\author{
Sue Black • Briony MacDonald-McMillan • Xanthe Mallett
}

Received: 23 October 2012 / Accepted: 29 January 2013 /Published online: 13 February 2013

(C) The Author(s) 2013. This article is published with open access at Springerlink.com

\begin{abstract}
When undertaking image comparison of the hand between accused and perpetrator, it is not unusual for scars to be identified on the back of the hand. To investigate the occurrence of scarring in a discreet sample, a database of 238 individuals was examined, and the dorsum of the right and left hands was gridded for each individual. The position, size and type of scar were recorded within each grid. It was found that, in general, males exhibited a higher incidence of scarring than females. However, males were more likely to show scarring on their left hand whereas females were more likely to exhibit scarring on their right hand. Contrary to the literature, scarring was not most prevalent along the borders of the hand but occurred more frequently in association with the index and middle finger corridor regions. Surgical scars were rare as were large scars whereas linear scars smaller than $6 \mathrm{~mm}$ were the most frequently identified. Close to half of the sample did not exhibit scarring on one hand. The importance of understanding the pattern of scarring on the back of the hand is discussed in the light of forensic image comparison analysis.
\end{abstract}

Keywords Scar · Hand · Anatomy $\cdot$ Image comparison · Offender

\section{Introduction}

The human hand is an effective and efficient manipulator of the environment with which it interacts [1]. Next to the face, the hand is the most familiar region of the body as it is frequently on display, rarely covered and is a source of familiarity through interpersonal communication and physical interaction [2].

S. Black $(\bowtie) \cdot$ B. MacDonald-McMillan $\cdot$ X. Mallett

University of Dundee, Dundee, UK

e-mail:s.m.black@dundee.ac.uk
Within the biometrics and forensic science communities, the hand has been widely accepted for its role in the verification of identity [3], particularly in relation to variation recognised in palmar and digital epidermal prints $[4,5]$. However, the dorsum of the hand has also proved to be of value for such purposes, and features that have been investigated include variation in knuckle skin crease patterns, pigmentation distribution and superficial vein patterns [6-9].

The basic function of this appendage is to interact with the immediate environment, and, as a result, it is vulnerable to physical insults that may alter or modify its appearance [10]. Over $20 \%$ of patients attending Accident and Emergency (A\&E) departments in the UK each year have a hand injury, which equates to over 1.36 million attendances each year, of which $5 \%$ will require surgery [11]. Isolated hand and wrist injuries accounted for $6.6 \%$ of all new A\&E admissions in Northern Ireland [12] with a consensus that probably between $10 \%$ and $20 \%$ of all admissions are related to hand injuries $[13,14]$. This general incidence rate appears to hold true in other countries with the research by Rosberg and Dahlin [15] in Malmo, Sweden, concurring that $12 \%$ of $A \& E$ admissions relate to hand injuries.

Rosberg and Dahlin [15] and Hill et al. [12] suggested that the demographic most at risk from hand injuries are young males between the ages of 11 and 25 years. Rosberg and Dahlin [15] also reported that injuries occur more frequently to the border regions of the hand and specifically to the thumb or small finger. It is reported that around $75 \%$ of the population is right-handed and $15 \%$ left-handed with the ability to be truly ambidextrous being relatively rare [16, 17]. The dominance of the hand is reported to have a significant influence of the incidence of injury with the dominant hand more likely to show injury than the nondominant hand. Hill et al. [12] agreed with this proposal but found that the non-dominant hand was at increased risk of injury when a knife was involved with a ratio of 1:3.4 for 
Table 1 Sample separated according to hand dominance and sex

\begin{tabular}{lllll}
\hline & Right-handed & Left-handed & Ambidextrous & Total \\
\hline Male & 156 & 21 & 0 & 177 \\
Female & 55 & 5 & 1 & 61 \\
Total & 211 & 26 & 1 & 238 \\
\hline
\end{tabular}

dominant to non-dominant hands. Other common causes of injury (broken glass, opening a tin, fall on hand, hand caught between objects, hand through window/door, etc.) showed a higher ratio of injuries to the dominant over the non-dominant hand. Sorock et al. [18] found that righthanded people injured their left hand in $55.4 \%$ of cases and left-handed people injured their right hand in $57.7 \%$ of cases.

It is generally held that scars resulting from medical intervention are of lesser value for verification purposes than scars that originate from an accidental aetiology as, for the former, there are common factors whereas accidental scars offer more random characteristics such as location, size, healing pattern, etc. [19-21]. Whilst most surgical scars can be readily differentiated from accidental scars mainly due to their appearance and position in relation to Langer's lines [22], in some

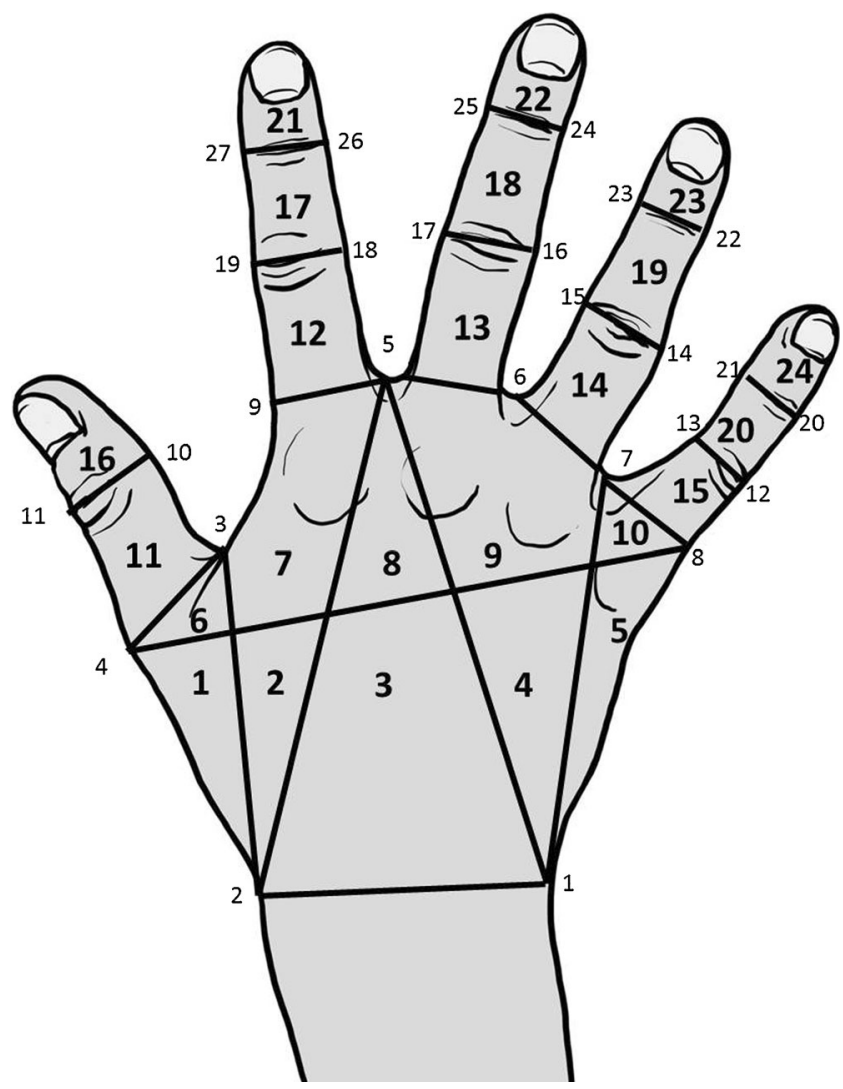

Fig. 1 Location of the 27 hand landmarks and the formation of the deformation grid that arises from these to result in 24 grid cells for recording purposes instances, especially if the scars are small, it may be difficult to diagnose aetiology with accuracy. However, in reality, the incidence of surgical scars is considered to be very small compared with accidental scars, the majority of which will never result in a visit to A\&E, let alone an operating theatre, and therefore, for the purposes of verification of identity, they may in fact be misrepresented in terms of their discriminatory value for the purposes of identification [19].

Within the biometrics and forensic science communities, the hand is viewed as being sufficiently individuating to fulfil the requirements for verification of identity but is considered to be of lesser value in the establishment of identity [23]. For the purposes of verification, two data sets are required that can be compared for features of similarity and difference. The strength of that relationship can then be expressed on the basis of likelihood ratios that the two sets either arise from the same individual or from a different individual [24-26]. Guidelines

Table 2 Definition of the points that permit construction of the hand grid

Landmark

1 Most medial point on wrist constriction

2 Most lateral point on wrist constriction

3 Deepest point in the interdigital webbing between digits 1 and 2

4 Most lateral and prominent point over the 1st metacarpophalangeal (MCP) joint

5 Deepest point in the interdigital webbing between digits 2 and 3

6 Deepest point in the interdigital webbing between digits 3 and 4

7 Deepest point in the interdigital webbing between digits 4 and 5

8 Medial border of the base of digit 5 parallel to the MCP joint

9 Lateral border of base of digit 2 parallel to the MCP joint

10 Medial border of thumb parallel to the interphalangeal (IP) joint

11 Lateral border of the thumb parallel to the IP joint

12 Medial border of digit 5 parallel to the proximal interphalangeal (PIP) joint

13 Lateral border of digit 5 parallel to the PIP joint

14 Medial border of digit 4 parallel to the PIP joint

15 Lateral border of digit 4 parallel to the PIP joint

16 Medial border of digit 3 parallel to the PIP joint

17 Lateral border of digit 3 parallel to the PIP joint

18 Medial border of digit 2 parallel to the PIP joint

19 Lateral border of digit 2 parallel to the PIP joint

20 Medial border of digit 5 parallel to the distal interphalangeal (DIP) joint

21 Lateral border of digit 5 parallel to the DIP joint

22 Medial border of digit 4 parallel to the DIP joint

23 Lateral border of digit 4 parallel to the DIP joint

24 Medial border of digit 3 parallel to the DIP joint

25 Lateral border of digit 3 parallel to the DIP joint

26 Medial border of digit 2 parallel to the DIP joint

27 Lateral border of digit 2 parallel to the DIP joint 


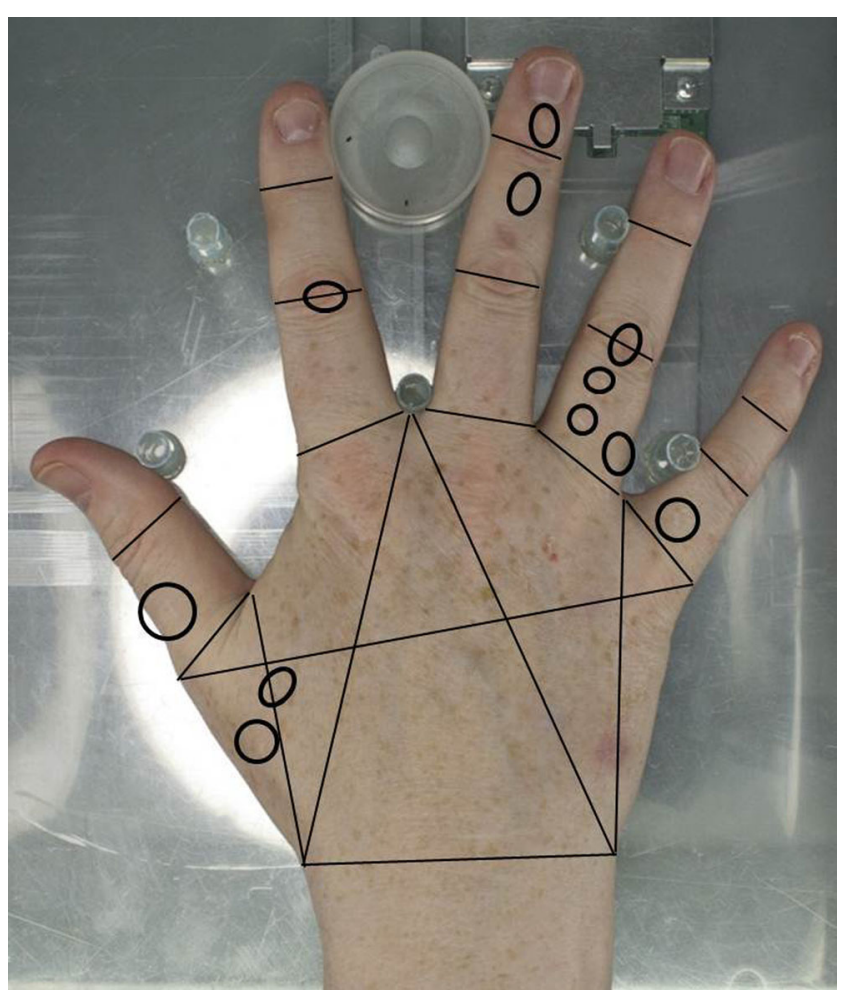

Fig. 2 Cropped image from the database of the right hand of a female participant. The deformation grid has been placed according to the landmark points (straight lines) and the positions of scars are outlined by black circles

for the forensic comparison of images within the UK were published by the National Policing Improvement Agency [27] on behalf of the Association of Chief Police Officers, and the document laid out several important considerations in relation to image comparison for the purpose of verification of identity in a legal setting. Although aimed at comparison of the face, this document applies equally well to comparison of other regions of the body including the hand. Image comparison depends strongly on the quality of the images, and the NPIA document stated that identification through comparison of images does not have 'evidential value unless it demonstrates morphologically comparable features'. It also highlighted the importance that such comparisons illustrate the significance of points of similarity and difference and that it must highlight presence and absence of features. Also highlighted in this report was the importance of probability factors and likelihood of features being present or absent in comparative images.

The presence of scarring on the dorsum of the hand has been utilised as a feature for consideration within the multifactorial process of hand image comparison. Within the Centre for Anatomy and Human Identification at the University of Dundee, image comparisons are undertaken of the anatomical features of the dorsum of the hand primarily for the purposes of comparing accused to offender images. In the majority of cases, these involve images of child sexual abuse where the dorsum of the hand of the perpetrator is present. The requirement for this form of analysis is on the increase with casework showing a tenfold rise in the past 5 years. The sharing of images of child pornography is recognised as one of the fastest-growing crimes of modern times $[28,29]$ with close to a million new photographs being posted on the Internet daily. Ease of access to the World Wide Web for the purposes of sharing images and the ease of availability of self-operated recording devices to perpetrators of sexual abuse is of concern to the law enforcement profession, as the sharing of images and the demand that is generated has added a new dimension to the social problem of child protection and the investigation and prosecution of child sexual offenses [30-33].

As scars are a common feature in the comparison of these images, it is essential that an understanding of their incidence is more fully understood. The aim of this research was to assess the incidence and position of scars on the dorsum of the hand to facilitate an understanding of the value of hand scars in the process of verification of identity. A subsequent publication will utilise this information and use it to construct likelihood ratios for current casework analysis.

Table 3 Number of scars found in each cell separated for sex and side

\begin{tabular}{|c|c|c|c|c|}
\hline Cell no. & Male right & Male left & Female right & Female left \\
\hline 1 & 4 & 21 & 5 & 1 \\
\hline 2 & 4 & 13 & 4 & 3 \\
\hline 3 & 13 & 13 & 6 & 8 \\
\hline 4 & 4 & 2 & 0 & 2 \\
\hline 5 & 3 & 1 & 0 & 0 \\
\hline 6 & 2 & 4 & 0 & 0 \\
\hline 7 & 14 & 31 & 13 & 3 \\
\hline 8 & 6 & 9 & 4 & 1 \\
\hline 9 & 26 & 18 & 7 & 6 \\
\hline 10 & 0 & 4 & 0 & 1 \\
\hline 11 & 10 & 19 & 5 & 2 \\
\hline 12 & 17 & 25 & 7 & 4 \\
\hline 13 & 17 & 13 & 7 & 3 \\
\hline 14 & 3 & 2 & 3 & 1 \\
\hline 15 & 8 & 16 & 3 & 2 \\
\hline 16 & 4 & 9 & 2 & 1 \\
\hline 17 & 27 & 34 & 13 & 3 \\
\hline 18 & 23 & 32 & 7 & 3 \\
\hline 19 & 12 & 8 & 2 & 0 \\
\hline 20 & 7 & 10 & 0 & 0 \\
\hline 21 & 22 & 18 & 3 & 2 \\
\hline 22 & 11 & 18 & 4 & 5 \\
\hline 23 & 12 & 13 & 0 & 0 \\
\hline 24 & 2 & 15 & 0 & 0 \\
\hline Total & 251 & 348 & 95 & 51 \\
\hline
\end{tabular}




\section{Material and methods}

The Centre for Anatomy and Human Identification at the University of Dundee holds an active database of hand images using both visual and infrared light. At the time of this research, the database consisted of images of pairs of hands from 260 individuals of both sexes drawn from a cadre of Disaster Victim Identification specialists undertaking training at the University of Dundee. The images were taken under good lighting conditions and at high resolution. Two hundred thirty-eight participants permitted personal information to be recorded, including sex and hand dominance, resulting in 177 males and 61 females (476 hands) being available for this research (Table 1). The age range for the sample was 2162 years with a mean age of 43 years, and all participants were of European ancestry. As per the expected incidence, approximately $10 \%$ were left-handed and close to $90 \%$ were righthanded. Any individual with single or multiple digit amputations was not included nor were any individuals with developmental or congenital abnormalities.

The dorsal surface of each hand was divided into 24 cells by way of a deformation grid, with each cell assigned an identification number (Fig. 1 and Table 2). Twenty-seven landmarks were selected to permit construction of this grid, and they were chosen because of their anatomical stability and visibility in all images. Once each hand was gridmapped, then the presence of scarring was recorded (Fig. 2). For each hand, the number, type and approximate size of a scar was recorded for each of the 24 cells, for both the right and left hand of each individual.

The number of scars was a simple count of the scars present within a grid. If a scar crossed a grid line, it was recorded within the grid where the majority of the scar resided. Therefore, no scar was counted twice. Scar type referred to whether the scar was linear or non-linear in its presentation. Size of the scar was assessed using the photographic scale marker included in each image. Scars $\leq 5 \mathrm{~mm}$ were classified as small, scars between 6 and $9 \mathrm{~mm}$ were medium and scars $\geq 10 \mathrm{~mm}$ were recorded as being large. Only inactive scars were counted, and recent injuries to a hand that still showed inflammatory reactions were not included.

\section{Results}

Table 3 shows the distribution of scar incidence across the 24 grid cells in the right and left hands of the males and

Fig. 3 Location of approximately $50 \%$ of scarring on the dorsum of the hand in right and left hands of males and females
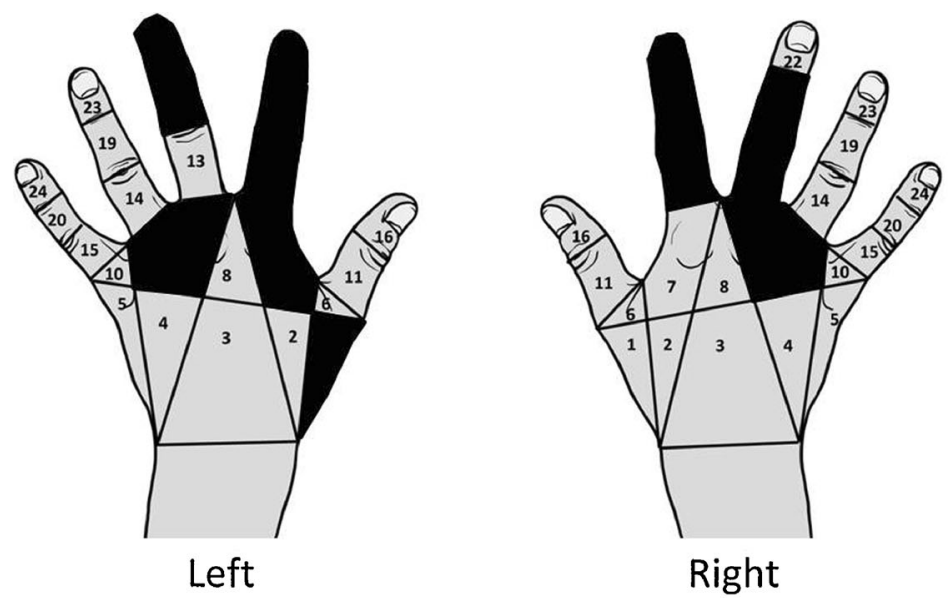

Male
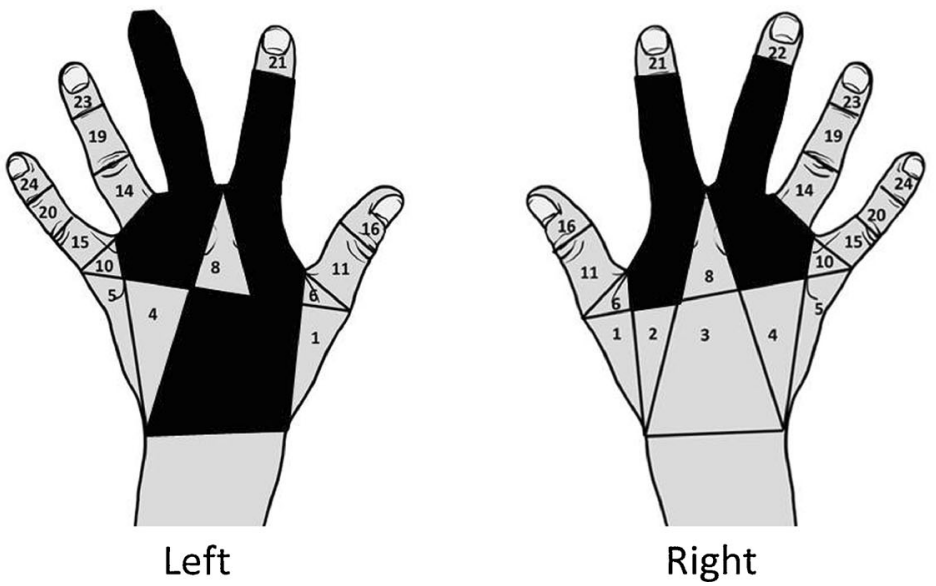

Female 
females from the sample. Linear and non-linear scars have been combined in this table so that a total of 251 scars were found in the male right sample (average of 1.42 scars per hand), 348 in the male left sample (average of 1.97 per hand), 95 in the female right sample (average of 1.56 per hand) and 51 in the female left sample (average of 0.84 per hand). Combining right and left hands resulted in an average of 3.38 scars for each male and 2.39 scars for each female. In reality, $49 \%$ of male right hands did not show any scarring nor did $40 \%$ of male left hands, $44 \%$ of female right hands or $57 \%$ of female left hands. Forty-five males were scar-free (25\% of male sample) showing scarring on neither their right nor their left hands whilst 16 females $(26 \%$ of female sample) were devoid of scarring on both hands. The largest number of scars seen in any one hand was 14 on a male right, 16 on a male left, 10 on a female right and 6 on a female left. The largest number of scars seen in the combined right and left hands of any individual was 23 on a male and 14 on a female. Mann-Whitney $U$ testing showed that scars were more common in males than females $(P<0.001)$, more common in male rights than male lefts $(P<0.001)$ and more common in female lefts than in female rights $(P<0.001)$.

Using the data in Table 3, Fig. 3 was constructed to show where approximately $50 \%$ of the scarring in each hand occurred. For male right hands, the highest incidence of scarring was found in grid cells 9, 17, 18 and 21 which equated to $39 \%$ of scarring. To raise the total to $53 \%$ scarring, grid cells 12 and 13 had to be added. For male left hands, the highest incidence of scarring was found in grid cells 7, 17 and 18 which equated to $28 \%$ of all scarring. To raise the total to $56 \%$ of all scarring, grid cells 1, 9, 12, 21 and 22 had to be added. For female right hands, the highest incidence of scarring was found in grid cells 7 and 17 which equated to $28 \%$ of all scarring. To raise the total to $55 \%$ of all scarring, grid cells 9, 12, 13 and 18 had to be added. For female left hands, the highest incidence of scarring occurred in grid cells 3, 9 and 22 which equated to $38 \%$ of all scarring. To raise the total to $46 \%$ required cells $2,7,12$, 13,17 and 18 to be added. When cells were examined for a common pattern in relation to where approximately $50 \%$ of scarring occurs, grid cells 9, 12, 17 and 18 were common to all four groups (side and sex) and grid cells 7 and 13 were common to three of the four groups. Figure 3 shows the common positions within the hand for the incidence of scarring, so that the distal region of the hand appears to be more commonly scarred, particularly in relation to the index and middle fingers.

Figure 4 shows the location of what can be described as the medial border (grid cells 5, 10, 15, 20 and 24), the lateral border (grid cells 1, 6, 11 and 16), the index finger corridor (grid cells 7, 12, 17 and 21) and the middle finger corridor (grid cells 9, 13, 18 and 22). Table 4 shows the incidence and location of scars in these regions separated by sex and

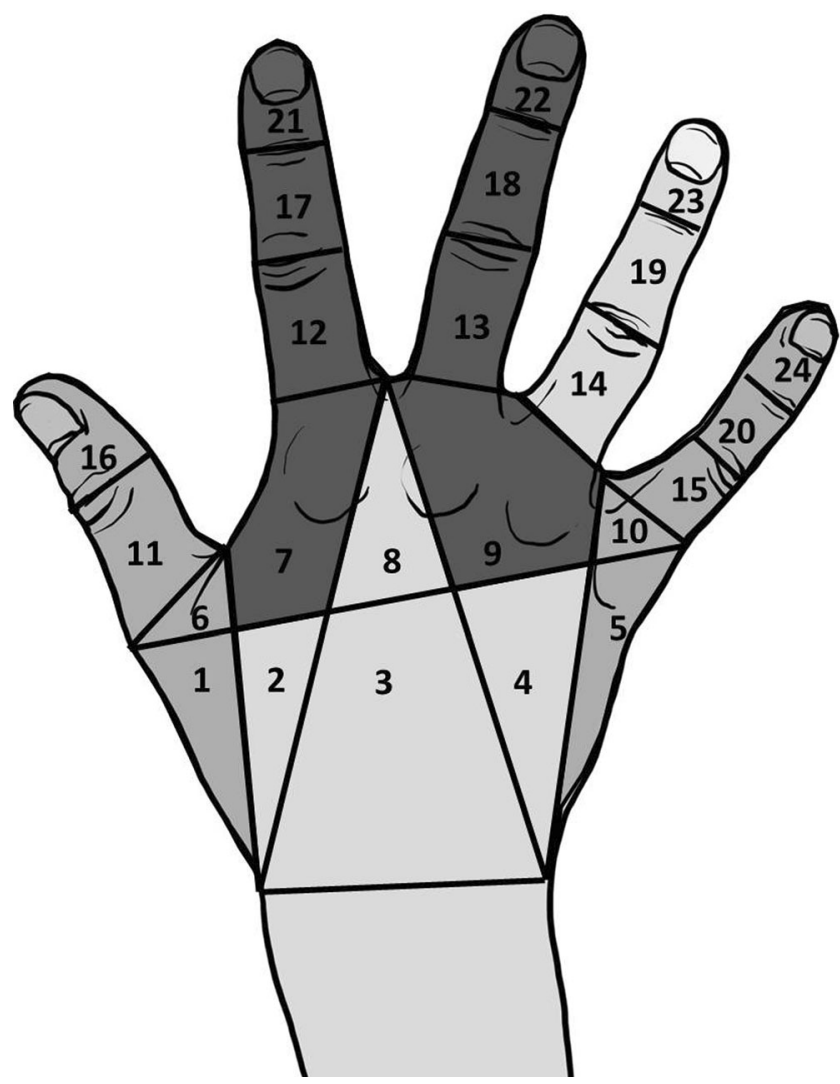

Fig. 4 Location of the medial and lateral border segments and the index and middle finger corridor regions

side. An average of $7 \%$ of all scars occur along the medial border, $8.5 \%$ along the lateral border, $31 \%$ in the index finger corridor and $33 \%$ in the middle finger corridor.

Tables 5 and 6 show the incidence of scars in each of the 24 grid cells separated by scar type and size for males and females, respectively. Table 5 shows that, in the male right hand, linear scars are more than twice as common as nonlinear scars and Mann-Whitney $U$ tests show this to be highly significantly different $(P<0.001)$. Linear scars are most commonly found in grid cells $9,12,17,18$ and 21 whereas non-linear scars are most frequently found in grid

Table 4 Percentage incidence of scarring in different regions of the hand for rights and lefts in both sexes

\begin{tabular}{|c|c|c|c|c|c|}
\hline & \multicolumn{2}{|l|}{ Male } & \multicolumn{2}{|c|}{ Female } & \multirow[t]{2}{*}{ Average } \\
\hline & Right & Left & Right & Left & \\
\hline $\begin{array}{l}\text { Index corridor cells } \\
7,12,17,21\end{array}$ & 32 & 31 & 38 & 24 & 31 \\
\hline $\begin{array}{l}\text { Middle corridor cells } \\
9,13,18,22\end{array}$ & 31 & 23 & 45 & 33 & 33 \\
\hline $\begin{array}{l}\text { Lateral border cells } \\
1,6,11,16\end{array}$ & 8 & 15 & 3 & 8 & 8.5 \\
\hline $\begin{array}{c}\text { Medial border cells } \\
5,10,15,20,24\end{array}$ & 8 & 13 & 3 & 4 & 7 \\
\hline
\end{tabular}


Table 5 Number of scars (linear and non-linear) in male right and left hands, in each cell, separated according to scar size

\begin{tabular}{|c|c|c|c|c|c|c|c|c|c|c|}
\hline \multirow[t]{2}{*}{ Cell no. } & \multicolumn{5}{|c|}{ Male right } & \multicolumn{5}{|c|}{ Male left } \\
\hline & Linear & Non-linear & Small & Medium & Large & Linear & Non-linear & Small & Medium & Large \\
\hline 1 & 4 & 0 & 0 & 4 & 0 & 13 & 8 & 9 & 5 & 7 \\
\hline 2 & 3 & 1 & 2 & 1 & 1 & 10 & 3 & 6 & 3 & 4 \\
\hline 3 & 12 & 1 & 3 & 7 & 3 & 9 & 4 & 8 & 3 & 2 \\
\hline 4 & 2 & 2 & 3 & 0 & 1 & 2 & 0 & 0 & 2 & 0 \\
\hline 5 & 2 & 1 & 2 & 1 & 0 & 1 & 0 & 1 & 0 & 0 \\
\hline 6 & 2 & 0 & 2 & 0 & 0 & 4 & 0 & 4 & 0 & 0 \\
\hline 7 & 13 & 1 & 4 & 5 & 5 & 26 & 5 & 15 & 12 & 4 \\
\hline 8 & 3 & 3 & 1 & 3 & 2 & 5 & 4 & 6 & 1 & 2 \\
\hline 9 & 16 & 10 & 17 & 8 & 1 & 12 & 6 & 13 & 5 & 0 \\
\hline 10 & 0 & 0 & 0 & 0 & 0 & 4 & 0 & 3 & 0 & 1 \\
\hline 11 & 8 & 2 & 4 & 5 & 1 & 15 & 4 & 7 & 10 & 2 \\
\hline 12 & 15 & 2 & 12 & 5 & 0 & 23 & 2 & 18 & 4 & 3 \\
\hline 13 & 12 & 5 & 14 & 2 & 1 & 12 & 1 & 8 & 3 & 2 \\
\hline 14 & 3 & 0 & 1 & 2 & 0 & 2 & 0 & 2 & 0 & 0 \\
\hline 15 & 5 & 3 & 6 & 1 & 1 & 14 & 2 & 8 & 5 & 3 \\
\hline 16 & 3 & 1 & 3 & 0 & 1 & 7 & 2 & 8 & 1 & 0 \\
\hline 17 & 16 & 11 & 24 & 2 & 1 & 32 & 2 & 26 & 4 & 4 \\
\hline 18 & 16 & 7 & 14 & 8 & 1 & 24 & 8 & 26 & 4 & 2 \\
\hline 19 & 10 & 2 & 9 & 2 & 1 & 8 & 0 & 6 & 2 & 0 \\
\hline 20 & 7 & 0 & 3 & 4 & 0 & 6 & 4 & 7 & 2 & 1 \\
\hline 21 & 17 & 5 & 17 & 5 & 0 & 14 & 4 & 14 & 4 & 0 \\
\hline 22 & 5 & 6 & 11 & 0 & 0 & 15 & 3 & 11 & 6 & 1 \\
\hline 23 & 5 & 7 & 11 & 1 & 0 & 13 & 0 & 8 & 5 & 0 \\
\hline 24 & 2 & 0 & 2 & 0 & 0 & 11 & 4 & 12 & 3 & 0 \\
\hline Total & 181 & 70 & 165 & 66 & 20 & 282 & 66 & 226 & 84 & 38 \\
\hline
\end{tabular}

cells 9 and 17. Small scars are the most common size (66\% of all scars in the male right hand) followed by medium scars ( $26 \%$ of all scars), and large scars were least common ( $8 \%$ of all scars). Small scars were most frequently found in grid cells 9,17 and 21 , with medium scars most frequently found in grid cells 3,9 and 18. If large scars did occur, then they were most frequently found in grid cells 3 and 7 . In the male left hand, linear scars were more common than nonlinear scars by a factor of over 4, and Mann-Whitney $U$ tests showed this to be highly significantly different $(P<0.001)$. Linear scars were found most frequently in grid cells 7,12 , 17 and 18 whereas non-linear scars were most frequently found in grid cells 1 and 18. Small scars were the most common (65\% of all scars) and were most frequently located in grid cells 12, 17 and 18. Medium scars were less common ( $24 \%$ of all scars in the male left hand) and were most commonly found in grid cells 7 and 11 whereas large scars were the least common (11\% of all scars) and occurred most frequently in grid cell 1.

Table 6 shows that, in the female right hand, linear scars are more than three times as common as non-linear scars, and Mann-Whitney $U$ tests showed this to be highly significant $(P<0.001)$. Linear scars are most commonly found in grid cells 7 and 17, and although non-linear do not have a high occurrence, they tend to be found in the same grid cells as linear scars. Small scars are the most common size (68\% of all scars in the female right hand) followed by medium scars ( $24 \%$ of all scars), and then large scars were least common ( $7 \%$ of all scars). Small scars were most frequently found in grid cells 7 and 17 with medium and large scars not showing a particularly high incidence in any grid cell. In the female left hand, linear scars were more common than nonlinear scars by a factor of almost 3 , and again this reached statistical significance $(P<0.01)$. Linear scars were found most frequently in grid cells 3 and 22 whilst non-linear scars were most frequently found in grid cell 9 . Small scars were the most common (65\% of all scars in the female left hand) and were most frequently located in grid cell 9. Medium scars were less common ( $29 \%$ of all scars), and large scars were the least common ( $6 \%$ of all scars). The incidence of medium and large scars did not permit identification of a most frequent grid cell. 
Table 6 Number of scars (linear and non-linear) in female right and left hands, separate according to scar size

\begin{tabular}{|c|c|c|c|c|c|c|c|c|c|c|}
\hline \multirow[t]{2}{*}{ Cell no. } & \multicolumn{5}{|c|}{ Female right } & \multicolumn{5}{|c|}{ Female left } \\
\hline & Linear & Lon-linear & Small & Medium & Large & Linear & Non-linear & Small & Medium & Large \\
\hline 1 & 5 & 0 & 1 & 3 & 1 & 1 & 0 & 1 & 0 & 0 \\
\hline 2 & 2 & 2 & 3 & 1 & 0 & 2 & 1 & 3 & 0 & 0 \\
\hline 3 & 5 & 1 & 1 & 4 & 1 & 5 & 3 & 4 & 3 & 1 \\
\hline 4 & 0 & 0 & 0 & 0 & 0 & 2 & 0 & 0 & 1 & 1 \\
\hline 5 & 0 & 0 & 0 & 0 & 0 & 0 & 0 & 0 & 0 & 0 \\
\hline 6 & 0 & 0 & 0 & 0 & 0 & 0 & 0 & 0 & 0 & 0 \\
\hline 7 & 9 & 4 & 10 & 2 & 1 & 3 & 0 & 1 & 2 & 0 \\
\hline 8 & 3 & 1 & 3 & 0 & 1 & 1 & 0 & 0 & 0 & 1 \\
\hline 9 & 6 & 1 & 6 & 0 & 1 & 1 & 5 & 6 & 0 & 0 \\
\hline 10 & 0 & 0 & 0 & 0 & 0 & 0 & 1 & 1 & 0 & 0 \\
\hline 11 & 5 & 0 & 5 & 0 & 0 & 2 & 0 & 1 & 1 & 0 \\
\hline 12 & 5 & 2 & 5 & 2 & 0 & 2 & 2 & 2 & 2 & 0 \\
\hline 13 & 5 & 2 & 5 & 2 & 0 & 3 & 0 & 3 & 0 & 0 \\
\hline 14 & 3 & 0 & 3 & 0 & 0 & 1 & 0 & 1 & 0 & 0 \\
\hline 15 & 3 & 0 & 1 & 1 & 1 & 2 & 0 & 1 & 1 & 0 \\
\hline 16 & 1 & 1 & 1 & 1 & 0 & 1 & 0 & 1 & 0 & 0 \\
\hline 17 & 9 & 4 & 9 & 3 & 1 & 2 & 1 & 2 & 1 & 0 \\
\hline 18 & 5 & 2 & 6 & 1 & 0 & 3 & 0 & 3 & 0 & 0 \\
\hline 19 & 2 & 0 & 1 & 1 & 0 & 0 & 0 & 0 & 0 & 0 \\
\hline 20 & 0 & 0 & 0 & 0 & 0 & 0 & 0 & 0 & 0 & 0 \\
\hline 21 & 2 & 1 & 3 & 0 & 0 & 2 & 0 & 2 & 0 & 0 \\
\hline 22 & 3 & 1 & 2 & 2 & 0 & 5 & 0 & 1 & 4 & 0 \\
\hline 23 & 0 & 0 & 0 & 0 & 0 & 0 & 0 & 0 & 0 & 0 \\
\hline 24 & 0 & 0 & 0 & 0 & 0 & 0 & 0 & 0 & 0 & 0 \\
\hline Total & 73 & 22 & 65 & 23 & 7 & 38 & 13 & 33 & 15 & 3 \\
\hline
\end{tabular}

Only three individuals presented with identifiable surgical scars ( $1.3 \%$ of the total sample), and all were found in males and classified as large scars. One was located on the left hand in grid cell 3, and the other two were located on the right and in grid cells 3 and 4 .

\section{Discussion}

The phrase 'the hand is the window onto the mind' has been attributed to the German philosopher Immanuel Kant from around $1798[34,35]$, and certainly, the analysis of the hand has intrigued science and the public alike through their portrayal in both art and literature. That the intimate anatomy of the hand can be of investigative value was exploited by Conan Doyle in his novel 'A study in scarlet' where Holmes pontificated that 'By a man's finger-nails, by his coat-sleeve, by his boots, by his trouser-knees, by the callosities of his forefinger and thumb, by his expression, by his shirt-cuff-By each of these things a man's calling is plainly revealed.'[36]. Whilst neither finger callosities nor nails form the core of this investigation, it is evident that the persistent scars on the back of the hand paint an interesting picture in terms of marks that can be utilised as present or absent morphological features in the comparison of images for the purposes of verification of identity.

Previous research has indicated that males are more likely to present a larger number of scars than females, and their location will be influenced by the dominance of the hand $[12,15,19]$. The results of this study agree with this in part. Approximately $50 \%$ more scars occurred in male hands than in female hands. Interestingly, although males showed a greater incidence on their left hands, females showed a greater incidence on their right hands. This is unlikely to be explained by hand dominance as it was shown in Table 1 that the percentage of hand dominance was similar in the two groups and agreed with the general literature. Therefore, there is a suggestion that the male left hand which is usually the non-dominant hand is more prone to injury than the dominant hand (right) whilst the reverse is the situation for females with the dominant hand being more susceptible to injury. It is possible that this result reflects differences in the 
type of injuries sustained by males and females [12, 18], and although this seems like a very stereotypical explanation, it is difficult to find a reasonable alternative other than males are more likely to scar their non-dominant hand as a result of perhaps injury caused by an implement in the dominant hand, whereas female scarring is less implement-based and more accidental in aetiology as described by Hill et al. [12].

It would appear from this research that, perhaps as expected, surgical scars are rare within the data base sample, and when they do occur, they are most commonly represented in cells 3 and 4 . The most common hand surgery is largely concerned with degenerative change including median nerve compression and arthritis [19], and this is more common in an elderly sample than is perhaps represented by the database cohort. On the dorsum of the hand, surgical intervention scars occur most frequently over the joint regions to address arthroplasty, but in this research, the most common surgical scars were in the region over the intercarpal joints. The database is not necessarily representative of the general population, and it is important that the database be increased significantly so that comparisons may be made within appropriate populational sectors.

For the purposes of verification of identity, it has been shown that non-linear scars are less common as are scars in excess of $6 \mathrm{~mm}$. Therefore, these categories may initially be thought of as being of greater discriminatory value, but in reality the multiplicity of small scars (such as seen in Fig. 2) and their random placing due to their accidental nature resulted in no multiple scar patterning within the database being identical to any other. Therefore, whilst in isolation, the larger and non-linear scars may prove to be of greater value; the pattern of location of two or more small scars has proved to be of considerable importance in the formation of a two-dimensional locational map.

Contrary to the findings of Rosberg and Dahlin [15], the medial and lateral borders of the hand are not the most common location for the persistence of scarring in this sample. Only $7-8 \%$ of all scarring occurred along a hand border, and this was equally true for males and females and for rights and lefts. However, the highest incidence of scarring occurred along the index and middle corridor regions, where $64 \%$ of all scarring in the hand was located. This is a clear indication that a large proportion of the scarring found in this sample has resulted from interaction injury with both dominant and nondominant fingers being susceptible to small scale traumas.

For the purposes of image comparison, scars are a useful trait to examine for presence or absence, similarity or differences in shape, size and position. They are most commonly accidental in nature and therefore not predictable per se, although the incidence of scarring along the index and middle fingers is likely to be higher than in any other part of the hand. In males, scars are more likely to occur in the index and middle finger corridors of the non-dominant hand, and in the majority of casework undertaken, we have identified that it is the left non-dominant hand of the perpetrator that tends to be captured in images, and in the majority of cases, it is the thumb, index and middle finger regions that are most frequently observed. Therefore, it is exceptionally important to be aware of the incidence of scarring in this region in the general population and how that might relate to the profile of the offender hand [37, 38]. It is accepted that the occupational origin of the individuals within a database will be important as it is likely that the more manual work that is undertaken then the greater will be the incidence of scarring. The database utilised in this communication is of considerable value, but ongoing additions to the resource from different societal sectors will allow future inferences to be made regarding the incidence of scarring in different groups. The subsequent paper will examine current casework and the probability that the perpetrator and suspect was the same person, based solely on scar-related information sourced from this communication. It is essential that the anatomical interpretation of features of the hand is fully documented if expert opinions are to be proffered on the likelihood of two individuals showing matching features.

Open Access This article is distributed under the terms of the Creative Commons Attribution License which permits any use, distribution, and reproduction in any medium, provided the original author(s) and the source are credited.

\section{References}

1. J. Napier Hands, revised edition. (1993) In: R.H. Tuttle (ed). Princeton University Press, New Jersey.

2. N.A. Spaun. Forensic biometrics from images and video at the Federal Bureau of Investigation. IEEE Conference on Biometrics: theory, applications and systems. Washington DC, 2007.

3. Bolle RM, Connell JH, Pankanti S, Rathka NK, Senior AW (2004) Guide to biometrics. Springer-Verlag, New York

4. Maltoni D, Maio D, Jain AK, Prabhakar S (2009) Handbook of fingerprint recognition, 2nd edn. Springer-Verlag, London

5. Tistarelli M, Nicons MS (2009) Advances in biometrics: Third International Conference. Springer-Verlag, Berlin

6. Black SM, Mallett X, Rynn C, Duffield N (2009) Forensic hand image comparison as an aid for paedophile investigations. Police Professional 184:21-24

7. Meadows H (2011) Vein pattern analysis for forensic human identification. University of Dundee, PhD Dissertation

8. B. MacDonald-McMillan, The quantification of dorsal hand features of interest to assist forensic human identification. MSc(Res) Dissertation, University of Dundee, 2011.

9. Nicol Baines K (2012) Dorsal knuckle crease pattern: utility for forensic human identification. University of Dundee, MSc (Res)

10. Lloyd GJ (1985) Acute management for the injured hand. Can Family Physician 31:557-559

11. M. Brennen, P. Burge, F. Burke, J. Dias, D. Elliot, J. Hobby, M. Matthewson, R. Savage, S. Watson, Hand surgery in the UK: manpower, resources, standards and training. Report of a working party. The British Society for Surgery of the Hand. http:// 
www.bssh.ac.uk/members/documents/ukhandsurgreport.pdf. Accessed August 2012.

12. Hill C, Riaz M, Mozzam A, Brennen M (1998) A regional audit of hand and wrist injuries: a study of 4873 injuries. Journal of Hand Surgery 23:196-200

13. Dias JJ, Garcia-Elias M (2006) Hand injury costs. Injury 37:10711077

14. Dickson JK, Morris G, Heron M (2009) The importance of hand anatomy in the accident and emergency department: assessment of hand anatomy knowledge I doctors in training. The $\mathrm{J}$ of Hand Surgery: Eur Volume 34:682-684

15. Rosberg HE, Dahlin LB (2004) Epidemiology of hand injuries in a middle-sized city in Southern Sweden: a retrospective comparison of 1989 and 1997. Scand J Plast and Reconstructive Surgery and Hand Surgery 38:347-355

16. Hardyck C, Petrinovich LF (1977) Left-handedness. Psychological Bull 84:385-404

17. McManus C (2003) Right hand. Left Hand, Phoenix, London

18. Sorock GS, Lombardi DA, Hauser RB, Eisen EA, Herrick RF, Mittleman MA (2001) A case-crossover study of occupational traumatic hand injury: methods and initial findings. Am J Ind Med 39:171-179

19. Clarkson J, Schaefer M (2007) Surgical Intervention. In: Thompson TJU, Black SM (eds) Forensic human identification: an introduction. CRC Press, Florida

20. Netscher DT, Gharbaoui I (2007) Hand and upper extremities. In: Britt LD, Trunkey DD, Feliciano DV (eds) Acute care surgery: principles and practice. Springer Science, New York

21. Rutty GN (2007) Trauma soft tissue. In: Thompson TJU, Black SM (eds) Forensic human identification: an introduction. CRC Press, Florida

22. Campbell BJ, Campbell DJ (2003) Care of acute lacerations. In: Taylor RB, David AK, Fields SA, Phillips DM, Scherger JE (eds) Family medicine: principles and practice. $6^{\text {th }}$ edition. SpringerVerlag, New York

23. Kizza JM (2010) Ethical and social issues in the information age, 4th edn. Springer-Verlag, London
24. Evett IW, Jackson G, Lambert JA, McCrossan S (2000) The impact of the principles of evidence interpretation on the structure and content of statements. Sci and Justice 40:233-239

25. Morrison GS (2011) Measuring the validity and reliability of forensic likelihood-ratio systems. Sci and Justice 51:91-98

26. Neumann C, Evett IW, Skerrett J (2012) Quantifying the weight of evidence from a forensic fingerprint comparison: a new paradigm. J R Stat Soc 175:371-415

27. National Policing Improvement Agency. Facial identification guidance. Association of Chief Police Officers. Available at: http:// www.acpo.police.uk/documents/crime/2009/200911CRIFIG01.pdf. Accessed August 2012.

28. Akdeniz Y (2008) Internet child pornography and the law: national and international responses. Ashgate Publishing, Surrey

29. L. Radford, S. Corral, C. Bradley, H. Fisher, C. Bassett, N. Howat, S. Collishaw, Child abuse and neglect in the UK Today. NSPCC report. Available from: http://www.nspcc.org.uk/Inform/research/findings/ child abuse neglect research PDF wdf84181.pdf. Accessed August 2012.

30. Calder MC (2004) Child sexual abuse and the Internet: tackling the new frontier. Russell House Publishing, London

31. Taylor M, Quayle E (2006) Child pornography: an Internet crime. Routledge, London

32. Powell A (2007) Paedophiles. Child Abuse and the Internet, Radcliffe, London

33. Davidson J, Gottschalk P (2011) Internet child abuse: current research and policy. Routledge, London

34. Sennett R (2009) The craftsman. Penguin, London

35. Tallis R (2003) The hand: a philosophical inquiry into human being. Edinburgh University Press, Edinburgh

36. Conan Doyle A (1887) A study in scarlet. Ward, Lock and Co, London

37. Denov MS (2003) The myth of innocence: sexual scripts and the recognition of child sexual abuse by female perpetrators. The $\mathrm{J}$ of Sex Res 40:303-314

38. Robertiello G, Terry KJ (2007) Can we profile sex offenders? A review of sex offender typologies. Aggression and Violent Behavior 12:508-518 